\title{
Association of HLA B8 with spontaneous resolution in sarcoidosis
}

\author{
M J SMITH, C W G TURTON, D N MITCHELL, M TURNER-WARWICK, L M MORRIS, \\ AND S D LAWLER
}

From the Department of Medicine (Thoracic Medicine), Cardiothoracic Institute, Brompton Hospital, and the Department of Cytogenetics and Immunogenetics, Institute of Cancer Research and Royal Marsden Hospital, London

ABSTRACT HLA may influence the natural history of some diseases. HLA frequencies have been compared in 164 healthy control subjects, 50 patients with sarcoid lung fibrosis, and 37 patients with sarcoidosis that resolved spontaneously. B8 was increased significantly in the resolved group compared to both healthy control subjects $(p<0.001)$ and the fibrotic group $(p<0.01)$. The results support the findings of other investigators, and are consistent with the hypothesis that inherited host factors, perhaps related to immune response, influence the clinical expression of sarcoidosis.

Investigation of HLA is of interest in sarcoidosis firstly because of the evidence that inherited factors may influence this disease, ${ }^{1}$ and secondly because of the involvement of immune mechanisms in its pathophysiology. ${ }^{2}$ The conflicting results of HLA population studies ${ }^{3-7}$ and the negative results of a study of 14 families $^{8}$ show that there is no definite association between HLA and the development of sarcoidosis. However, HLA may influence the natural history of some diseases, ${ }^{9}$ and an increase in B8 frequency has been reported in patients with acute sarcoidosis presenting with erythema nodosum or arthropathy or both. ${ }^{10}$ In this paper we describe a comparison of HLA frequencies in patients with sarcoidosis according to whether the disease resolved spontaneously or progressed to fibrosis.

\section{Methods}

The records of patients with sarcoidosis who had been seen over a period of at least two years at the Brompton Hospital or neighbouring chest clinics were reviewed. Those who satisfied the criteria for each of the following groups were HLA typed. In all cases histological support was obtained from Kveim test, tissue biopsy or both.

GROUP 1 (SPONTANEOUS RESOLUTION)

1 Clinical features consistent with sarcoidosis. ${ }^{11}$
2 Chest radiograph consistent with sarcoidosis: (i) bilateral hilar and/or paratracheal lymphadenopathy (BHL), (ii) diffuse pulmonary mottling \pm BHL, (iii) no evidence of fibrosis (vide infra).

3 Loss of all symptoms with complete resolution of the chest radiograph without treatment.

GROUP 2 (LUNG FIBROSIS)

1 Clinical features consistent with sarcoidosis.

2 Chest radiograph showing: (i) loss of volume of both upper lobes, (ii) multiple irregular linear shadows, (iii) tracheal deviation and/or distortion of fissures, (iv) widespread mottling persisting for more than two years and failing to resolve completely with cortico-steroid treatment.

All the patients were white and unrelated. The clinical details of the two groups are summarised in table 1 .

Table 1 Clinical details of the sarcoidosis groups

\begin{tabular}{lrlr}
\hline Group I (resolved spontaneously) & Group 2 (lung fibrosis) & \\
\hline Total & 37 & Total & 50 \\
Male & 18 & Male & 28 \\
Female & 19 & Female & 22 \\
Age at presentation (years) & & Age at presentation (years) & \\
$\quad$ mean & 33 & mean & $21-52$ \\
$\quad$ range & $21-57$ & range & 50 \\
Chest radiograph at presentation: & Histological confirmation & \\
BHL only & 29 & & \\
BHL+mottling & 5 & & \\
Mottling only & 3 & & \\
Histological confirmation & $32(+5) \dagger$ & &
\end{tabular}

†The Kveim biopsies from five patients showed a follicular granulomatous response which was regarded as "equivocal" because of the presence of birefringent material. 
The healthy control subjects were 93 female and 71 male white hospital and laboratory workers aged between 18 and 63 years.

Lymphocytes were separated from heparinised blood over Ficoll Triosil and tissue typed by a standard two-stage microlymphocytotoxicity method. ${ }^{12}$ The typing sera conformed to the standards of the Seventh Histocompatibility Workshop and defined 14 antigens of the A locus, 17 antigens of the $B$ locus, BW4, and BW6.

HLA frequencies were compared using the chisquare test with Yates correction. Significance was not held to be established unless an a priori interest for the specificity already existed.

\section{Results}

The frequencies and relative risk values of the HLA specificities for which significant differences between the groups were found are shown in table 2. B8 was increased in the sarcoidosis resolved group compared with both healthy control subjects $(\mathrm{p}<0.001)$ and the fibrotic group $(p<0.01)$. B7 was reduced in the resolved group compared with healthy controls $(\mathrm{p}<0.05)$.

The results for Group 1 (resolved group) were analysed further. Thirty-four had BHL and $21(61 \%)$ of these were B8. Twelve had erythema nodosum and nine $(75 \%)$ of these were B8. Two patients had arthralgia, erythema nodosum, and BHL and both were B8. There was no correlation between B8 and sex or age at presentation.

\section{Discussion}

The problem in the interpretation of HLA population studies is what probability can be accepted as significant because very many comparisons are made. Association should only be regarded as established when an initial study shows a specificity to be of a priori interest, and this is confirmed by a second independent study. B8 frequency was reported to be increased in a study of patients presenting with acute

Table 2 Frequencies of specificities where significant differences were found

\begin{tabular}{lccll}
\hline Group & $\begin{array}{l}\text { Number of Frequency } \\
\text { patients }\end{array}$ & $\begin{array}{l}\text { F } \\
\%\end{array}$ & $\begin{array}{l}\text { Relative } \\
\text { risk }\end{array}$ \\
\hline Total controls & 164 & & & \\
Total sarcoid resolved & 37 & & & \\
Total sarcoid fibrotic & 50 & & $<0.05$ & 0.33 \\
B7 controls & 54 & 32 & & \\
B7 sarcoid resolved & 5 & 14 & $<0.001$ & 4.46 \\
B8 controls & 38 & 23 & & \\
B8 sarcoid resolved & 21 & 57 & $<0.01$ & \\
B8 sarcoid fibrosis & 13 & 26 & & 3.74 \\
B8 sarcoid resolved & 21 & 57 & & \\
\hline
\end{tabular}

sarcoidosis ${ }^{10}$ which included the results from a previous investigation. ${ }^{6}$ The patients included a group with erythema nodosum, B8 in seven (58\%) of 12 patients; a group with arthritis, B8 in nine $(82 \%$ ) of 11 patients, and a group who showed chest radiographic resolution, $\mathrm{B} 8$ in $28(50 \%)$ of 56 patients. The frequency of B8 in those with BHL was not given, though it is probable that this was a frequent feature. B8 may be regarded as a specificity of a priori interest after these results, and the B8 association with spontaneous resolution found in the present study is probably real. This association was not reflected in previous population studies. ${ }^{3-5}$ ? These studies were retrospective and may have included a high proportion of patients with chronic sarcoidosis.

The present results do not suggest that $\mathrm{B} 8$ protects from fibrosis since the frequencies in the fibrotic group and healthy controls were similar. B8 may relate to some favourable characteristic while other unknown factors influence the development of fibrosis. The comparability of the resolved and fibrotic groups with regard to, for example, BHL, is uncertain. The natural history of BHL is associated characteristically with a favourable course but it is not possible to compare the groups in this retrospective study with regard to BHL since it may have occurred silently earlier in the course of patients who presented with pulmonary mottling or fibrosis. It would be interesting to study a group of patients presenting with BHL only and which failed to resolve.

The aetiology of sarcoidosis is unknown. Many agents may cause a nonspecific granulomatous response. There is evidence that a transmissible factor is involved in some cases of sarcoidosis. ${ }^{13}$ One hypothesis that may explain the protean clinical manifestations of the disease is individual variability of immune responses to causative agents. The present findings of an association between B8 and BHL which resolves are consistent with such a hypothesis.

\section{References}

1 British Thoracic and Tuberculosis Association. Familial association in sarcoidosis. Tubercle 1973; 54:87-98.

2 Turner-Warwick M. Immunology of the lung. London: Edward Arnold, 1978; 148.

3 Hedfors E, Möller E. HLA antigens in sarcoidosis. Tissue Antigens 1972; 3:95-8.

4 Kueppers F, Mueller-Eckhardt C, Heinrich D, Schwab B, Brackertz D. HLA antigens of patients with sarcoidosis. Tissue Antigens 1974; 4:56-8.

5 Persson I, Ryder LP, Nielsen LS, Svejgaard A. The HLA A7 histocompatibility antigen in sarcoidosis in relation to tuberculin sensitivity. Tissue Antigens $1975 ; 6: 50-3$. 
6 Brewerton DA, Cockburn C, James DCO, James DG, Neville E. HLA antigens in sarcoidosis. Clin Exper Immunol 1977; 27:227-9.

7 McIntyre, JA, McKee KT, Loadholt CB, Mercurio $L$, Lin I. Increased HLA-B7 antigen frequency in South Carolina blacks in association with sarcoidosis. Transplant Proc, Suppl 1 1977; 9:173-6.

8 Turton CWG, Morris L, Lawler SD, Turner-Warwick M. HLA in familial sarcoidosis. In: Jones-Williams $\mathrm{W}$, Davies BH, eds. Proceedings of the 8th International Conference on Sarcoidosis and other Granulomatous Diseases. Cardiff: Alpha Omega, 1980: 195-200.

9 Falk J, Osoba D. The HLA system and survival in malignant disease-Hodgkin's disease and carcinoma of the breast. In: Murphy GP, ed. Progress in clinical and biological research. Vol 16. HLA and malignancy. New York: Alan R Liss, 1977; 205.

10 Neville E. HLA antigens and disease. Mount Sinai $J$ Med 1977; 44:772-7.

11 Scadding JG. Sarcoidosis. London: Eyre and Spottiswoode, 1967.

12 Kissmeyer-Nielsen F, Kjerbye KE. Lymphocytotoxic microtechnique in histocompatibility testing. Curtoni ES, Mattiuz PL, Tosi RM, eds. Copenhagen : Munksgaard, 1967, 381.

13 Mitchell DN, Rees RJW, Goswami, KKA. Transmissible agents from human sarcoid and Crohn's disease tissues. Lancet 1976; 2:761-5. 